\title{
el hormigón pretensado en puentes de ferrocarril
}

Iniciamos hoy,

y concluiremos en el próximo número, la publicación de una serie de realizaciones de puentes bajo carril, construídos en hormigón pretensado, en el ámbito universal.

Sus soluciones, de gran variedad formal y técnica, lucen desde 1943, en que se construyeron los primeros puentes pretensados en Suiza, la perfección de su técnica y funcionamiento.

En esta primera parte, sirve de introducción la puesta en evidencia de la eficiencia de esta nueva técnica y material, que viene a reunir en sí gran número de ventajas de las soluciones metálicas y de hormigón armado, eliminando mucho de los inconvenientes de ambos materiales. 
Pese a los pocos años de vida

del puiente pretensado, destaca, a continunación, el autor, el gran número dé realizaciones efectuadas en numerosos países, haciendo, en realidad; el primes capílulo de la

Historia Universal de puentes pretensados para ferrocarril.

Termina esta primera parte, con la descripción y exposición grálica de las-más destacadas soluciones de puentes de tramo sencillo.

En el próximo número, como continuación del tema publicaremos la serie de puentes de tramo continuo, para terminar, tras una breve conclusión, con una documentada bibliografía sobre el tema. 


\section{el hormigón pretensado en puentes

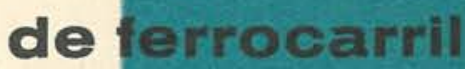

CARLOS FERNANDEZ CASADO, ingeniero de caminos

\section{introducción}

La natural prudencia ferroviaria contra las innovaciones de todo gén decálaje lógico entre las aplicaciones de los avances de la técnica constru rretera y puentes de ferrocarril. Esto ocurre en el caso del hormigón pr dejar sentado desde el principio que ya en el año 1943 se construyen en tes bajo carriles.

Los recelos especiales que en esta técnica del hormigón pretensado rroviarios, en cuanto a su aplicación a puentes, son los relativos a dos las sobrecargas correspondientes a trenes de ferrocarril: importancia dad de fatiga de los materiales.

Con respecto al primer punto, hay que tener en cuenta que si bien permite reducir la sección transversal de los elementos, trabajando a flexión, especialmente por la disminución notable del espesor de las almas de las vigas, en cambio los espesores de los forjados resultan comparables, y lo mismo las alturas de los elementos, cuando no se trata de altura estricta. Cuando tiene lugar esta condición, se puede reducir la altura en el caso de pretensado, lo cual es una de sus ventajas más importantes; pero no planteándose este problema, las alturas económicas son comparables. Además, si se sigue el criterio de colocar espesor de balasto análogo al del resto de la plataforma, lo cual no se ha generalizado, pues existen bastantes puentes pretensados en los que carriles se apoyan sobre el tablero sin intermedio del balasto, la transmisión de efectos dinámicos a la estructura queda muy aminorada. En todos los puentes de hormigón pretensado que conocemos, se ha adoptado el mismo coeficiente de impacto que en puentes de hormigón armado.

En cuanto a la reducción de resistencia admisible de los materiales por trabajar a esfuerzos repetidos, es preciso aclarar que con pretensado total, es decir, sin tracciones en el hormigón, no puede haber alternancia de tensiones en ninguno de los dos materiales. Precisamente una de las ventajas más importantes del hormigón pretensado, es que el cambio de tensión en el acero por actuación de las sobrecargas resulta insignificante con relación a la tensión de trabajo permanente y esto hasta tal punto que el aumento de tracción correspondiente no se tiene en cuenta en los cálculos, pues resulta siempre inferior a la disminución por pérdidas de pretensado desde la transmisión inicial.

En el hormigón la repetición de una sobrecarga máxima haría variar la tensión en fibra inferior entre la tensión admisible y cero, no llegando a alcanzar dicha tensión si la hipótesis de sobrecarga no es la más desfavorable. 
Concretando en valores numéricos para ambos materiales, supongamos una tracción admisible en acero de $100 \mathrm{~kg} / \mathrm{mm}^{2}$ y una compresión admisible de $80 \mathrm{~kg} / \mathrm{cm}^{2}$ que son límites muy aceptables. Si las pérdidas de pretensado son del orden del $15 \%$ habrá que tesar a $118 \mathrm{~kg} / \mathrm{cm}^{2}$, con lo cual hay una reducción de $18 \mathrm{~kg} / \mathrm{cm}^{2}$ respecto de la tensión a la transmisión del pretensado que nos sirve de prueba de los alambres. Si suponemos la sección bien dimensionada, tendremos en fibras extremas unas variaciones desde 0 a $80 \mathrm{~kg} / \mathrm{cm}^{2}$, como máximo, para actuación de sobrecargas, en pretensado total. Por consiguiente, las variaciones de la tensión del acero en contacto con dicho hormigón, suponiendo un coeficiente de amplificación $m=8$, puesto que se trata de acciones instantáneas y de un hormigón de coeficiente de elasticidad elevado, vienen dadas por la disminución de compresión en el hormigón multiplicadas por dicho coeficiente, o sea, $80 \mathrm{~kg} / \mathrm{cm}^{2} \times 8=640 \mathrm{~kg} / \mathrm{cm}^{2}=6,4 \mathrm{~kg} / \mathrm{mm}^{2}$, es decir, aproximadamente la tercera parte de las pérdidas, con lo cual no llega a alcanzar la tensión de tesado inicial. Pero, además, el tanto por ciento de variación de la tensión de trabajo es el $6,4 \%$ y, por consiguiente, insignificante en lo que puede suponer fenómeno de fatiga. El hormigón pasa mientras tanto de 80 a 0 para volver a $80 \mathrm{~kg} / \mathrm{cm}^{2}$ en fibra inferior para una resistencia de rotura de $300 \mathrm{~kg} / \mathrm{cm}^{2}$, lo cual lo aleja con toda seguridad de dicho fenómeno.

En las zonas donde existan momentos flectores de sentido contrario, los efectos en ambos materiales son los mismos, la variación en las tensiones de los aceros insignificantes, en este caso por encima y por debajo de la tensión de trabajo, pero con la misma amplitud, o mejor dicho menor, puesto que las secciones donde existe alternancia de momentos no corresponde a las de solicitaciones máximas, que son las que determinan las máximas tensiones en el hormigón.

En cambio, si se tratara de vigas de hormigón armado normal, nuestro acero estaría trabajando a tracciones variando desde 5 a $12 \mathrm{~kg} / \mathrm{mm}^{2}$ suponiendo una sobrecarga algo superior a la carga permanente con un tanto por ciento de variación del $140 \%$, lo mismo que el hormigón de la zona comprimida (para esto podemos suponer tensiones de $30 \mathrm{a} 72 \mathrm{~kg} / \mathrm{cm}^{2}$ ), mientras que el hormigón de la zona estirada estaría fuera de servicio por agrietamiento. En la zona de momentos flectores alternativos, esta alternancia se propaga a las tensiones de trabajo de los materiales que invierten ambos el sentido de su deformación, pudiendo el hormigón pasar de un trabajo por compresión a un trabajo por tracción, que produce su agrietamiento. El tanto por ciento de variación puede ser sencillamente del $200 \%$. En estas condiciones puede llegarse a la fatiga con tensiones admisibles normales, si el número de repeticiones de la sobrecarga pasa de un cierto valor.

Vemos, por consiguiente, la gran ventaja del hormigón pretensado en lo que se refiere a fatiga, lo cual se ha confirmado en todas las experiencias realizadas con cargas repetidas o alternativas, llegándose a la conclusión de que, mientras no se pase de la carga de agrietamiento, no hay lugar a considerar el fenómeno de la fatiga, y como en pretensado total no existen tracciones en fibras extremas, se está a cubierto de la fisuración.

Ya que hemos encontrado una de las ventajas del hormigón pretensado en puentes, enumeraremos las restantes para terminar esta introducción. Los materiales que constituyen el hormigón armado pretensado son de mucha mejor calidad, el hormigón de resistencia elevada obtenida gracias a una ejecución cuidadosa mediante control del cemento, dosificación de áridos en tres tamaños, vigilación rigurosa en la cantidad de agua y consolidación por vibración. El acero es siempre de una fabricación esmerada y se somete a pruebas de recepción sistemáticas fáciles, ya que, dado su pequeño diámetro, la fuerza necesaria para romperlo es reducida. Pero esta prueba se lleva a cabo de un modo automático al efectuar el tesado, porque, como ya hemos visto numéricamente, la tensión en servicio resulta siempre inferior a la que tuvo al transmitir el pretensado y ésta queda muy próxima al límite elástico aparente del acero. Además, tenemos otra comprobación de calidad al medir el alargamiento de los aceros, que es uno de los modos de controlar el pretensado. En el hormigón tenemos algo parecido, puesto que la fibra inferior trabaja muchas veces a tensión superior que la que ha de tener en servicio. 
La ausencia de agrietamiento lo hace especialmente apto para el caso de puentes propiamente dichos, es decir, sobre ríos en los que la atmósfera húmeda hace más temible el peligro de la oxidación de las armaduras, especialmente en la cabeza inferior de las vigas, que es la de tracción en las soluciones de vano sencillo y le corresponde una proporción de vano mayor en las soluciones continuas. No sólo desaparece el riesgo de agrietamiento, sino que la impermeabilidad es mucho más elevada al estar sometidas las fibras inferiores a una tensión de importancia de modo permanente. Esta misma ventaja se presenta en el caso de pasos sobre vías de comunicación, particularmente sobre ferrocarriles, construcción de vapor donde no es preciso encarecer la mejora de alejar radicalmente los aceros de la agresividad del humo.

Otra gran ventaja del hormigón pretensado de hacer posible el prefabricado, se ha utilizado para la transformación de puentes sin perturbar el tráfico, o bien para construir pasos sobre vías de comunicación causando el mínimo perjuicio al tráfico inferior.

La otra ventaja de permitir alturas de tablero más reducidas también se ha utilizado en todos los casos donde se impone la altura estricta, como ocurre en los pasos superiores de vías de comunicación. Otras ocasiones son también utilizadas como, por ejemplo, ocurrió en la sustitución de tableros de algunas líneas de los ferrocarriles ingleses, para adaptarlas al gálibo de electrificación, que resultaba muy ajustado en algunos puentes construídos sin haber previsto la utilización futura.

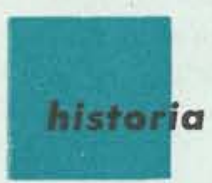

Ya hemos indicado que los primeros puentes de hormigón pretensado bajo vías se llevaron a cabo por los ferrocarriles federales suizos en los años 1943-44. • Después han construído un gran número con estructuras de tramos aislados y continuos y especialmente los pórticos con pilares inclinados o con células triangulares de extremidad.

La segunda nación que construye puentes ferroviarios es Bélgica, que en 1947 utiliza la construcción de los enlaces ferroviarios de Bruselas para ejecutar una losa experimental de $20,07 \mathrm{~m}$ de luz en el paso sobre la calle de Miroir. ${ }^{\circ}$ Esta losa se subdividió en fajas de 3,65 m de ancho, que se ejecutaron con arreglo a diversas técnicas de hormigón armado: normal con acero dulce, normal con acero Isteg, normal con acero Toristeg y pretensado. 
Proyecto y dirección estuvieron a cargo de Magnel, y durante su construcción se hicieron experiencias de toda clase, siendo visitado por gran número de ingenieros, dada la facilidad de encontrarse en la propia ciudad de Bruselas. En la actualidad han llegado hasta los 49,02 de luz récord en vano sencillo.

Los ingleses también empezaron en época temprana. En 1947 construyen un puente de cuatro vanos de unos $9 \mathrm{~m}$ * para sustituir a uno de madera sin alterar el tráfico, utilizando elementos premoldeados transportados desde taller. Esta solución la han repetido en gran número de ocasiones, aprovechando la menor altura de vigas en la sustitución de puentes, al electrificar las líneas, lo cual exigía la altura estricta. Han llegado a una luz de $48,80 \mathrm{~m}$, en Rohterham * que es el récord en puentes de tablero inferior.

Los alemanes realizaron el primer puente importante en 1950 sobre el Neckar en Heilbronn * con estructura continua de cinco vanos de luces, variando desde 18,15 a 21,57 m. Se ha llegado a una luz de 65,10 metros * en pórtico de un vano para doble vía de ferrocarril metropolitano.

Los franceses no se lanzaron de un modo decisivo en la primera época, pero han conseguido dos de los puentes de mayor importancia y belleza: el de La Voulte *, con vanos de $60 \mathrm{~m}$, salvados mediante pórticos trapeciales y el de Abidjan * con doble tablero para carretera y ferrocarril superpuestos en vanos de 46,50 metros.

En Estados Unidos se empezó tardíamente por las mismas razones que en puentes de carretera. El primero fué una losa de $6,10 \mathrm{~m}$, construída en 1954 para la Chicago Burlington \& Quincy. Han llegado a la luz de 21,33 * en un puente de dos tramos independientes en la Air Force Academy de Colorado Spring.

En América del Sur tenemos en Brisal el Puente Juazeiro para carretera y ferrocarril con diecinueve vanos, unos de tramo sencillo con luces de 25 y $32,70 \mathrm{~m}$ y dos grupos de tramo continuo de trece vanos y otro de tres con luces extremas de 34,60 e intermedias de 44,80 m. En Méjico existe un puente importante para carretera y ferrocarril sobre el río Coatzacoalcos, y varios puentes con luces comprendidas entre 20 y 35 metros en la línea Chihuahua-Pacífico.

En Rusia existe una colección de modelos de puentes para ferrocarril con luces comprendidas entre 12 y 27 metros, habiéndose construído en 1957 (World Conference of Prestressed Concrete de San Francisco) ciento cincuenta puentes bajo carriles.

- De todos los puentes marcados con asteriseo, se dan detalles en láminas y fichas bibliográficas. 

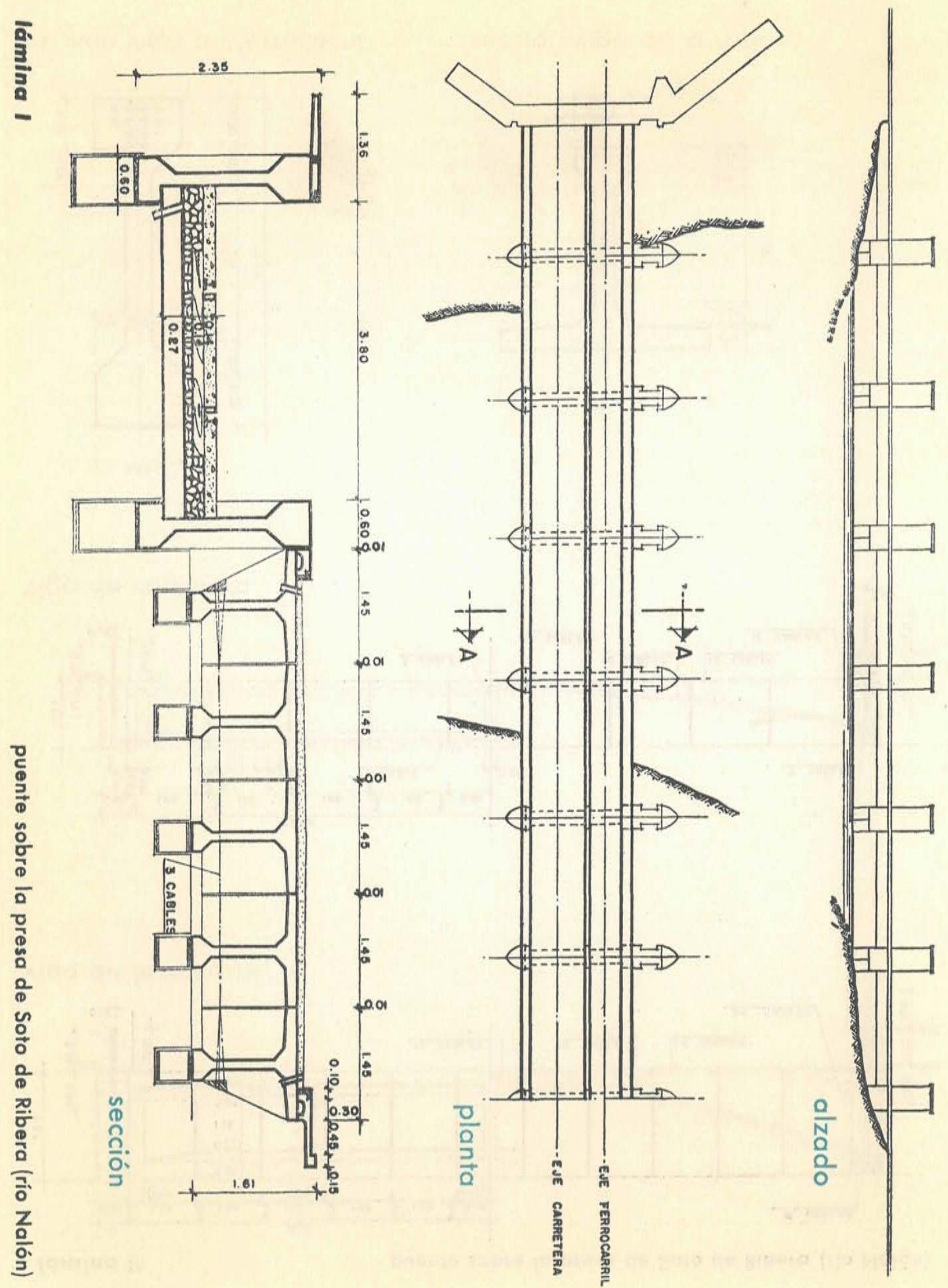
Iámina ||

puente sobre la presa de Soto de Ribera (río Nalón)

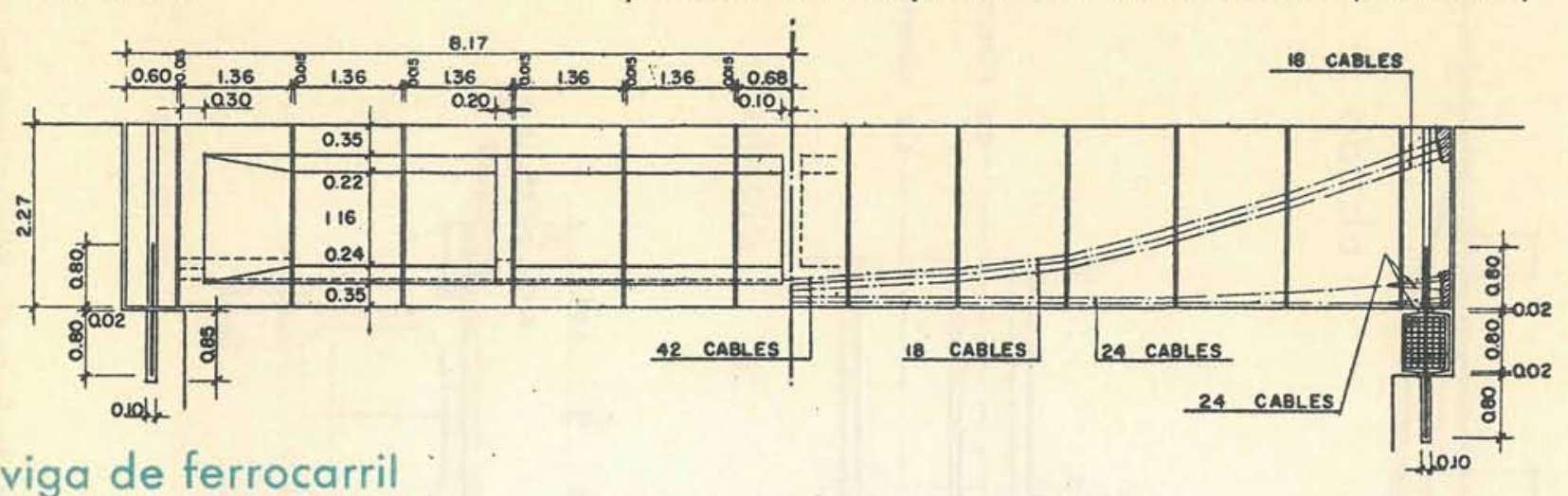

viga de ferrocarril

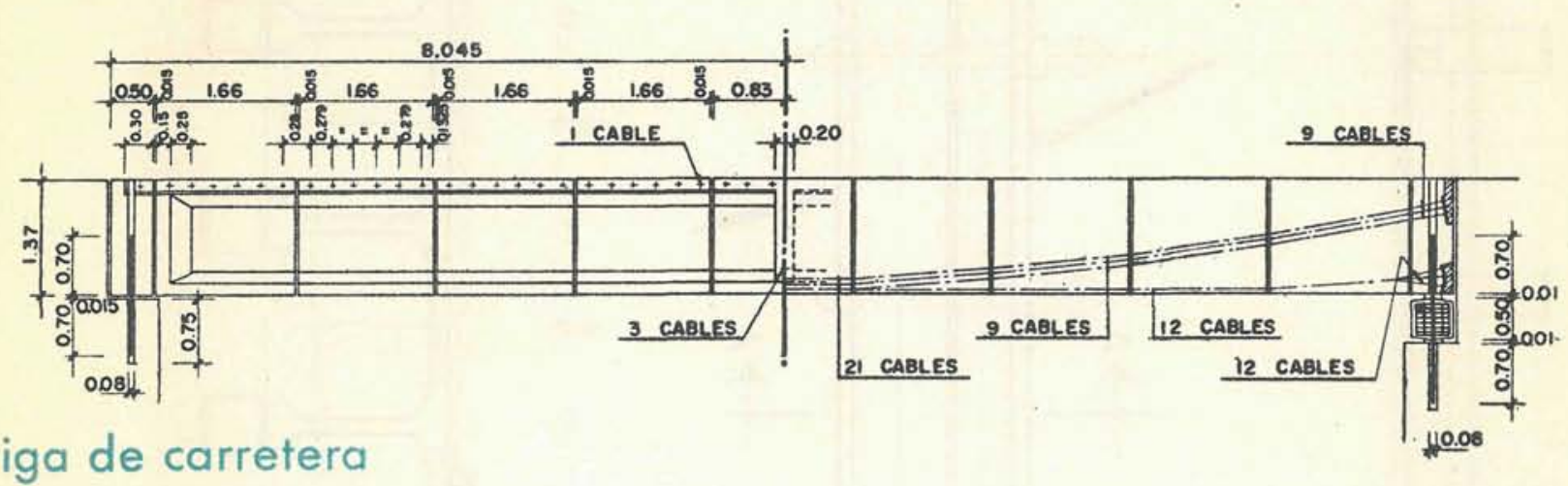

viga de carretera

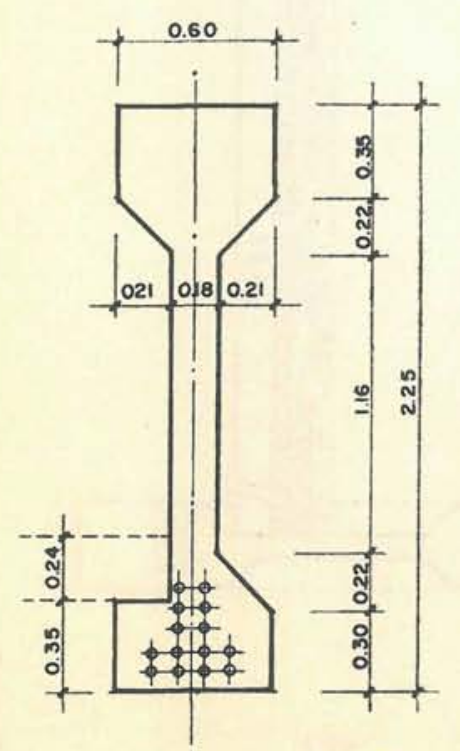

sección viga de ferrocarril

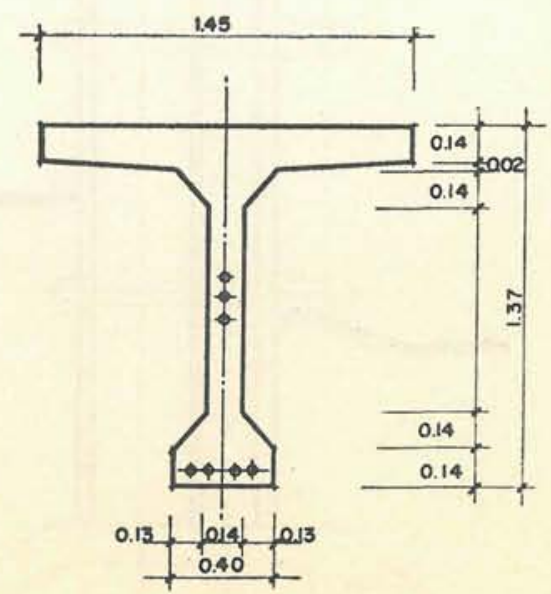

sección viga de carretera 


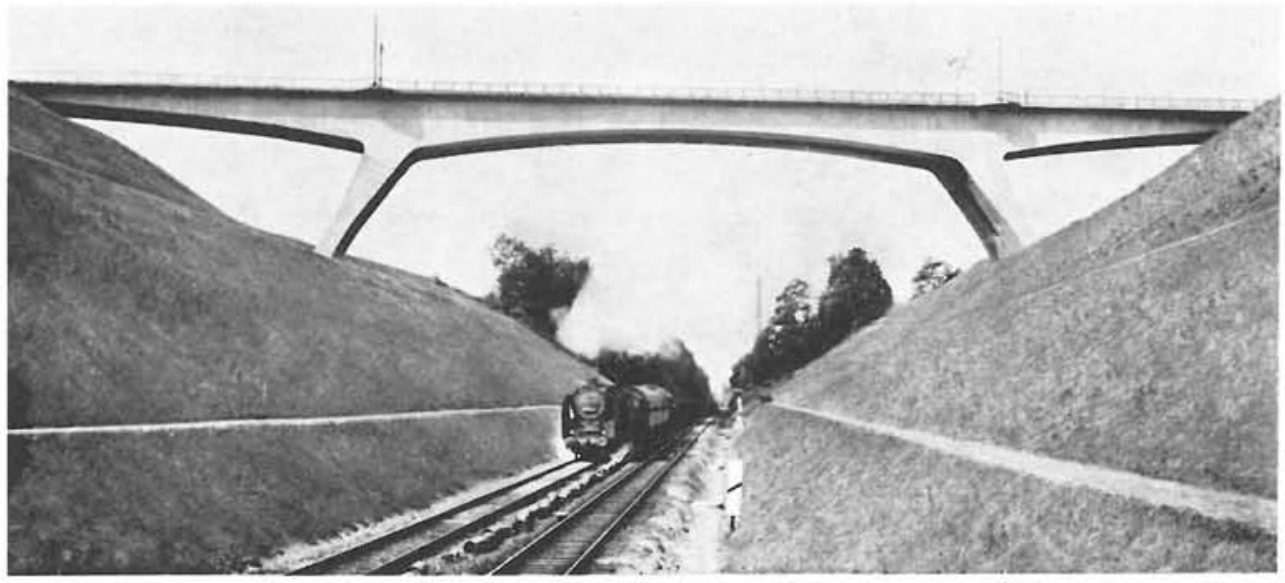

\section{Iámina III}

Viaducto ferroviario de Horremer. - Finteswalder-Diwidag - Luz, $85,50 \mathrm{~m}$.

Puente carretera - ferrocarril
de Abidjain.-Esquillan-Boussiron.-Luz, $46,50 \mathrm{~m}$.

Puente de La Voulte sobre el Ródano.-Luz, $60 \mathrm{~m}$.
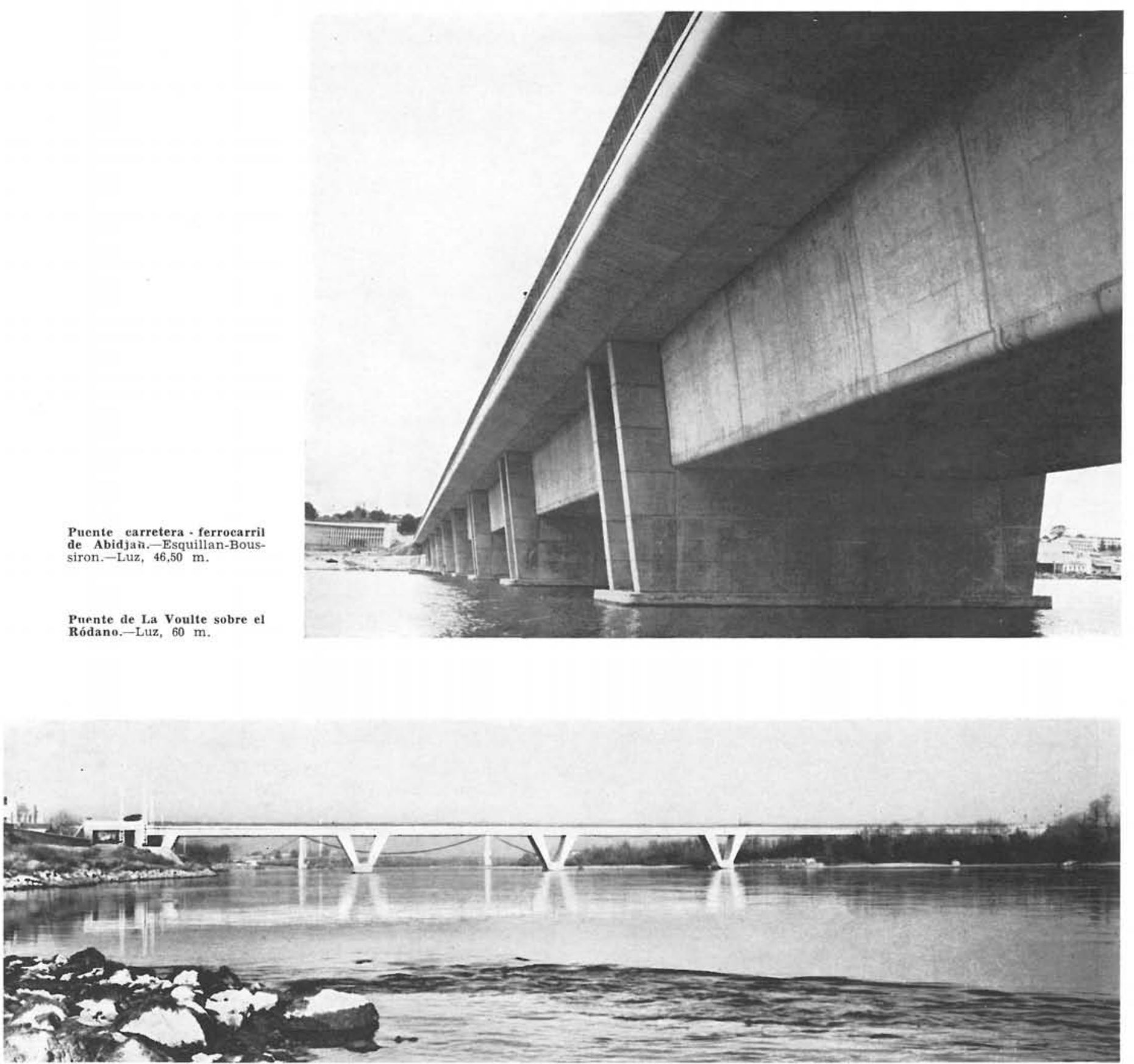
Uno de ellos, en Leningrado, tenía $52 \mathrm{~m}$ de luz con articulaciones. El mayor puente construído es de tableros superpuestos para carretera y ferrocarril metropolitano, con luces de $45+108+45$ más viaductos de acceso que suman una longitud de 848. La zona central se construyó en dos mitades, longitudinales en una de las orillas, llevándose por flotación hasta colocarlas sobre las pilas construídas «in situ».

En la India se ha construído recientemente un puente de ocho vanos de losa con luces de $12 \mathrm{~m}$ y vigas doble $\mathrm{T}$ prefabricadas.

En España no se ha construído ningún puente bajo carriles, pero la mayor parte de las aplicaciones son a pasos de carretera sobre ferrocarril: paso de la carretera de La Coruña sobre la línea del Norte en Las Rozas; paso de camino privado de ENASA sobre el ferrocarril de circunvalación, y actualmente está en construcción la cobertura de la estación del Paseo de Gracia en Barcelona, que, en realidad, es un puente de gran anchura para el tren de sobrecargas extraordinarias de carreteras. Además se ha comenzado la construcción de un puente de ferrocarril sobre las compuertas de la presa del Nalón para la central de Soto Ribera, en Asturias, con cinco vanos de $16 \mathrm{~m}$ para simple vía, con tablero inferior. (Láminas I y II).

Vamos a pasar rápidamente revista a las características principales de los distintos tipos de puentes construídos agrupados en: tramos sencillos, tramos continuos y pórticos.

Tramo sencillo. Láminas III a XV.-La mayor luz que conocemos en este tipo de puentes es la del puente Cherg sobre el Escalda, con 49,02 de luz teórica y tablero superior con sección cajón bicelular. Está flanqueado por dos vanos de $10 \mathrm{~m}$, ejecutados con vigas pregabricadas sección doble T. (Lámina XII).

En luces medias hasta unos $20 \mathrm{~m}$ se utiliza el tablero de losa ejecutándose con gran frecuencia por tiras prefabricadas enlazadas transversalmente, generalmente con aligeramientos circulares o rectangulares como se indica en lámina 5, o bien con elementos en T invertida que después se rellenan de hormigón «in situ». (Lámina VI).

En los tableros de vigas lo más normal es el forjado superior, constando de dos vigas por vía, aunque a veces no hay coincidencia entre planos de vigas y planos de carriles. En luces importantes es muy frecuente la sección en cajón con dos o tres tabiques verticales por vía. Sección típica de este género es la de los puentes marmolizados en Checoslovaquia. (Lámina VIII). Sección extraordinaria la del paso superior de la Air Force Academy, que es récord en Estados Unidos, con vigas prefabricadas que soportan un tablero «in situ», teniendo aquéllas doble sección trapecial.

También se utiliza la sección transversal con tablero inferior, habiéndose llegado a los 46,50 m en el puente de Roterham (Inglaterra), que es, además, oblicuo.

Existen puentes mixtos de carretera y ferrocarril con plataformas en el mismo tablero, como ocurre en los de Juazeiro o el del Rhin en Untervaz, pero el más interesante es el de Abidjean en Costa de Marfil, con dos secciones en cajón que albergan en su interior cada una de las vías y se construyó prefabricando tramos completos en una de las orillas y transportándolos por flotación a su lugar definitivo. Se trata de ocho vanos de 46,50 $\mathrm{m}$ de luz entre ejes de apoyos, habiendo problemas interesantes en los tramos intermedios de enlace entre ambas plataformas. (Láminas XIII, XIV y XV).

La relación c.e altura del tablero a luz oscila entre 1/13 a 1/19 en losas, $1 / 11$ a 1/13 en vigas con tablero superior, llegando a 1/14 en sección cajón y limitándose de 1/8 a 1/13 en tablero inferior. El espesor de los tabiques va de 0,17 a 0,25, el de las vigas, desde 40 a $70 \mathrm{~cm}$, y el espesor medio del forjado es de 25 centímetros. 
los primeros puentes ferroviarios construidos

PASO SUPERIOR DE SALAND, SUIZA (1942)

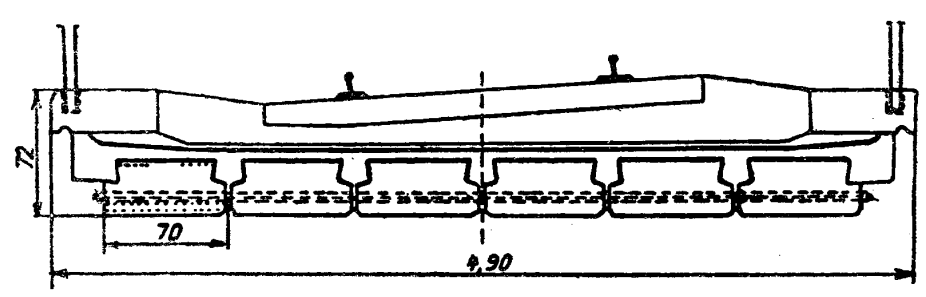

PASO SUPERIOR ESTACION BADEN, SUIZA (1943)
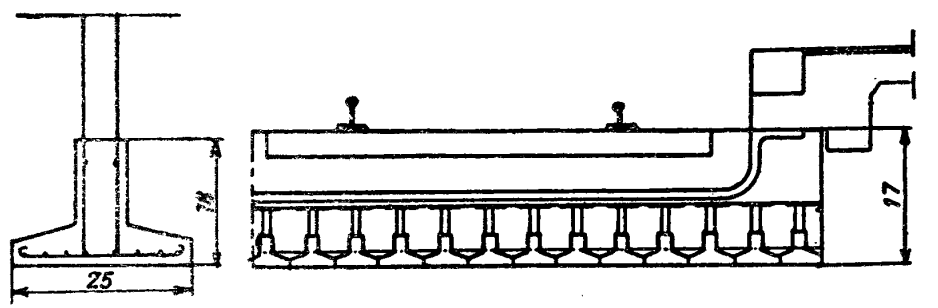

PUENTE DE LA CALLE MIROIR EN BRUSELAS (1949)

14 cables de $56 \varnothing 5 \mathrm{~mm}$

7 cables de $56 ₫ 5 \mathrm{~mm}$

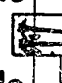

8 cables co
$56 \$ 5 \mathrm{~mm}$

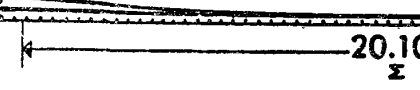

$z$

20.10

ALZADO

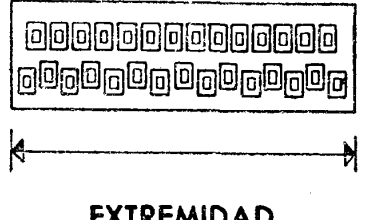

$$
\begin{array}{r}
4 \\
1.10 \\
1
\end{array}
$$

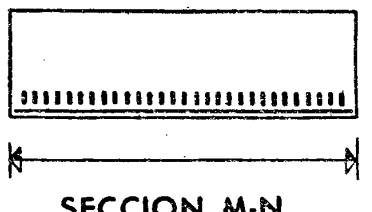

4

1.10

EXTREMIDAD

SECCION M-N 


\section{lámina V}

primeros puentes construídos en Alemania

PUENTE DEL NECKAR EN HEILBRONN (1950). - LUCES DE 18,15 A 21,57 M.

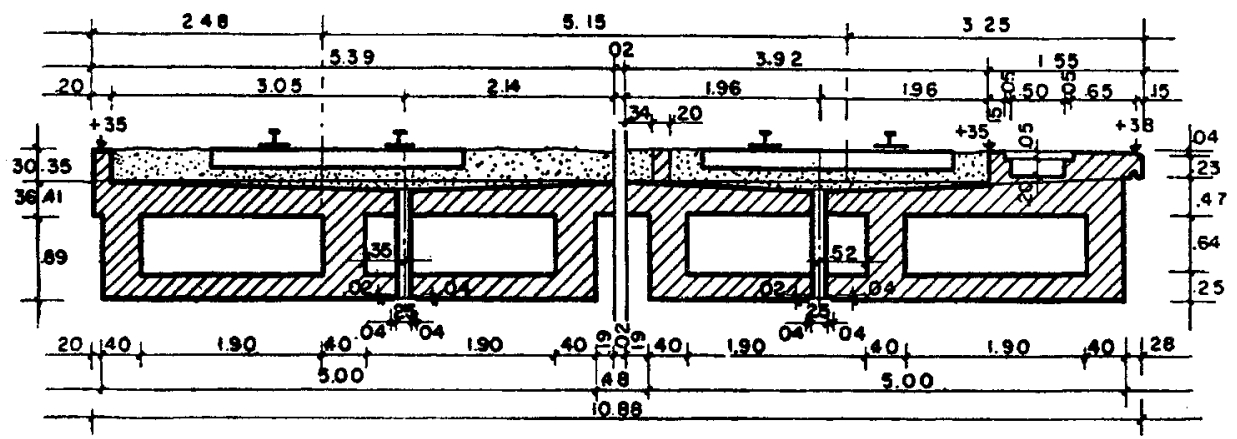

PUENTE SOBRE EL WUPPER EN KUPPERSTEG. - (195I).- LUZ 21,40 M.
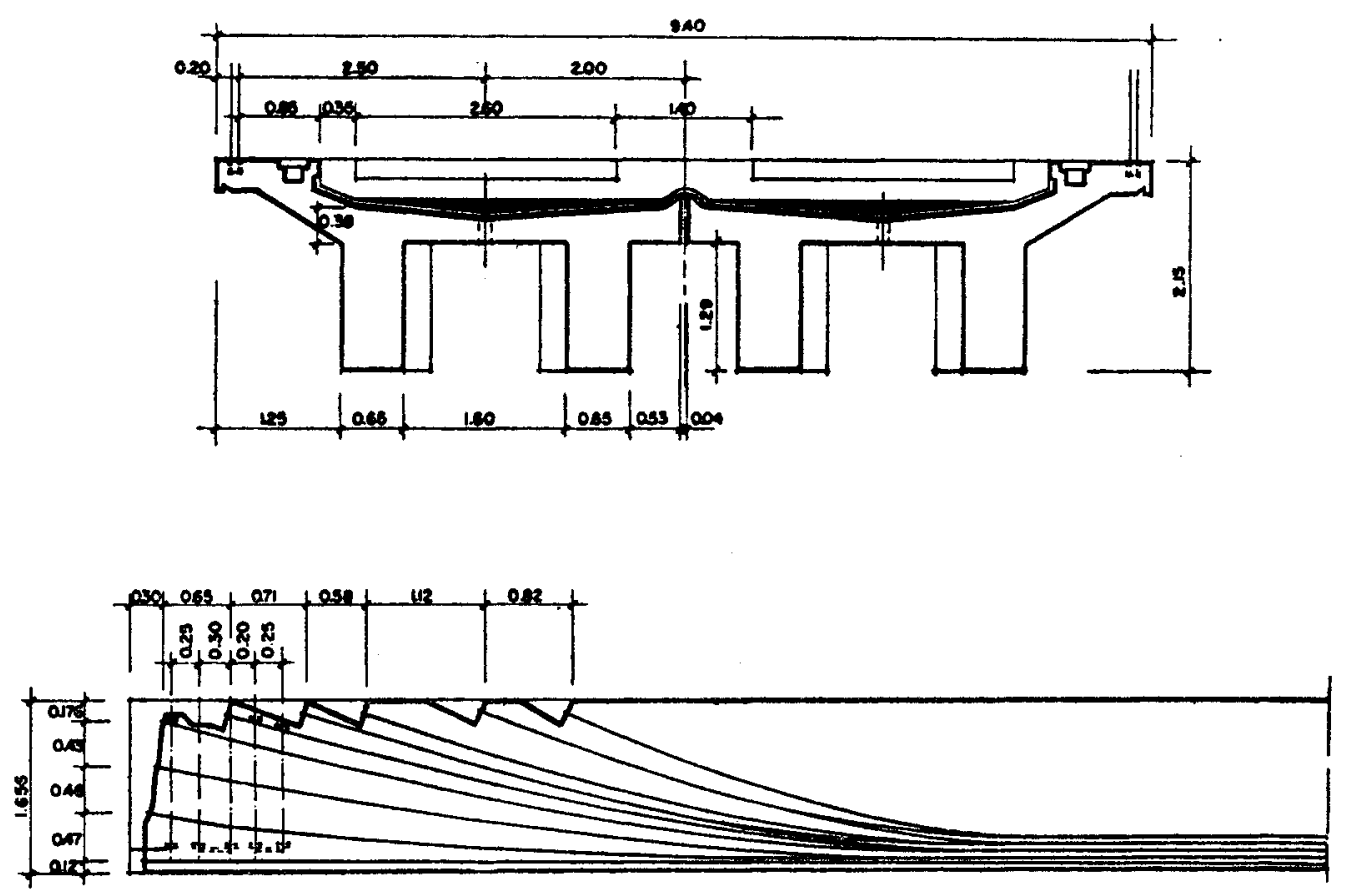
secciones transversales de tablero de F. C. Alemanes

PASO HOHNSTORF, EN HAMBURGO

LUZ $10,40 \mathrm{M}$.
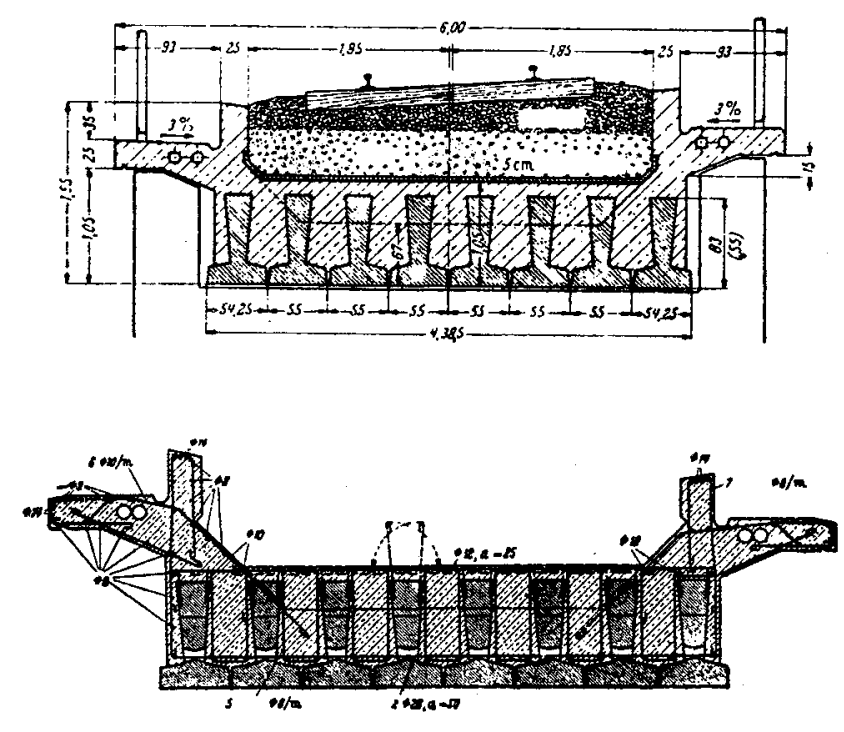

PASO ZUCKERDAMM, EN HAMBURGO

LUZ $21,50 \mathrm{M}$.

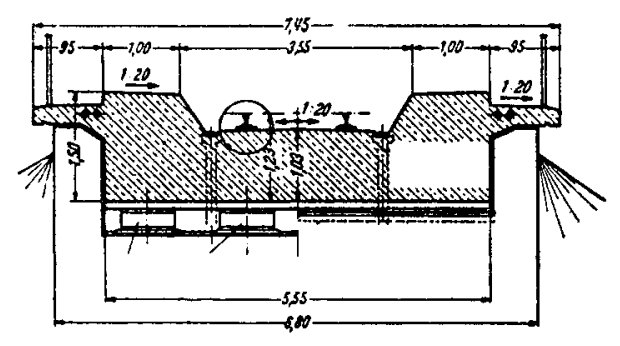

PUENTE SOBRE EL NIERS EN COLONIA-CLEVES

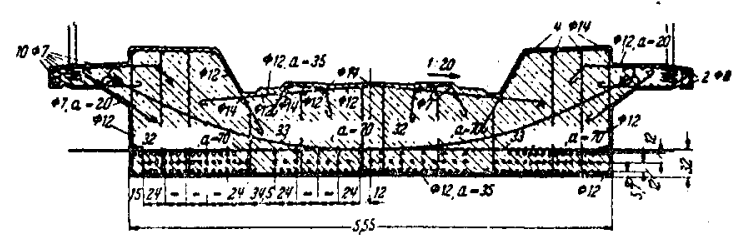


lámina VII

puentes de ferrocarril en U.S.A.

SOUTHERN R. R

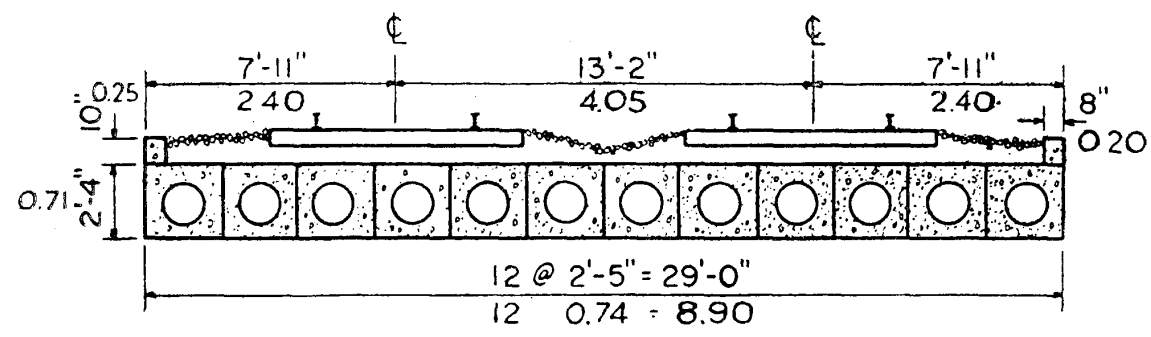

PELICAN ISLAND - GALVESTON R R

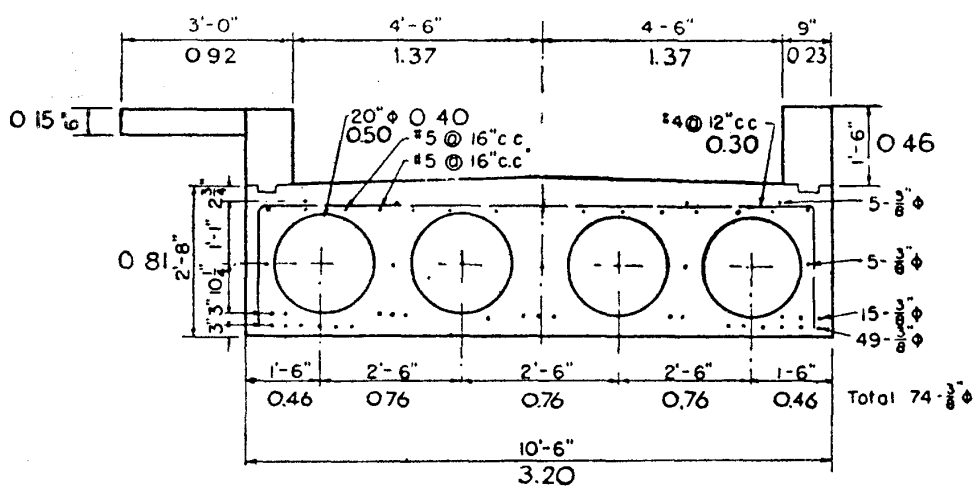

C. STREET ENCOLTON.-SANTA FE R. R.

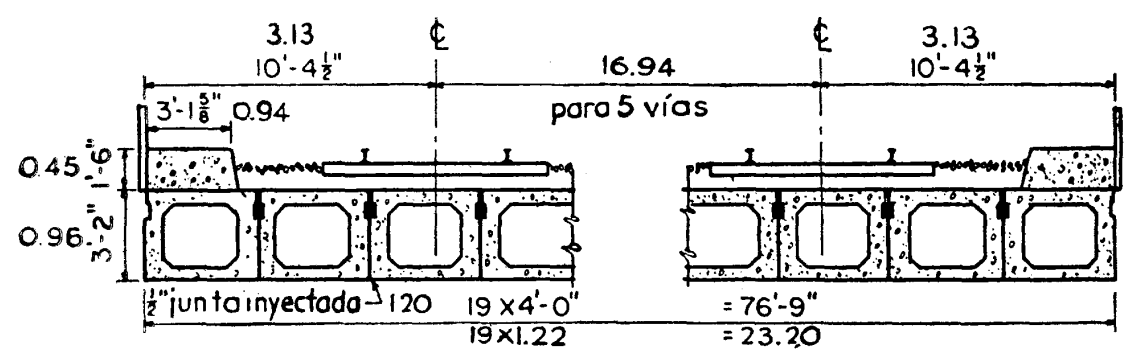




\section{lámina VIII}

PUENTE TIPO DIWIDAS EN RAIM (ALEMANIA)


SECCION DE PUENTE LOSA

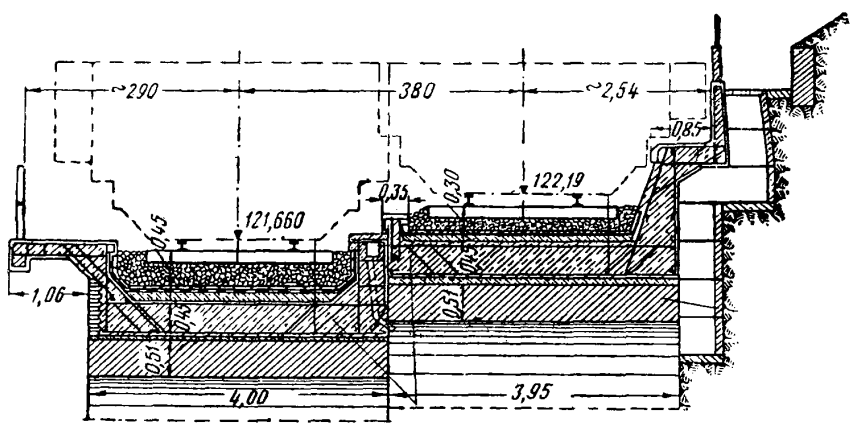

MODELOS NORMALIZADOS DE $10 \mathrm{M}$. Y 12,50 M. DE LUZ SECCIÓN CAJON CHECOSLOVAQUIA

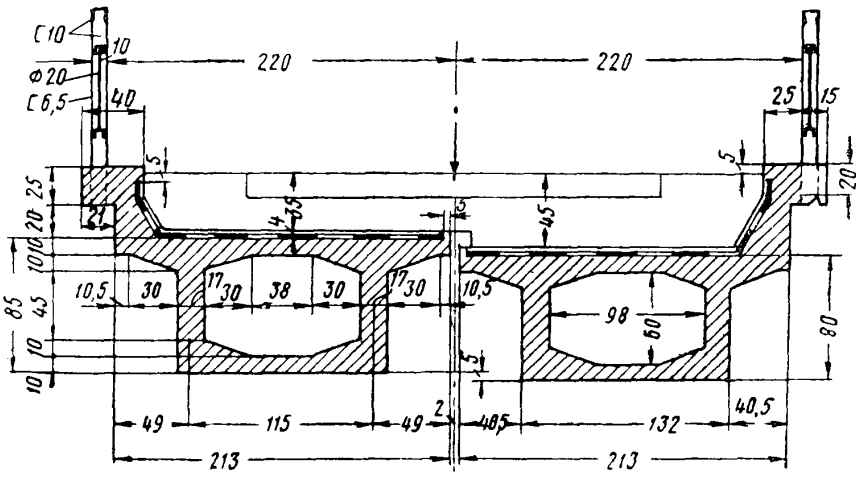




\section{lámina IX}

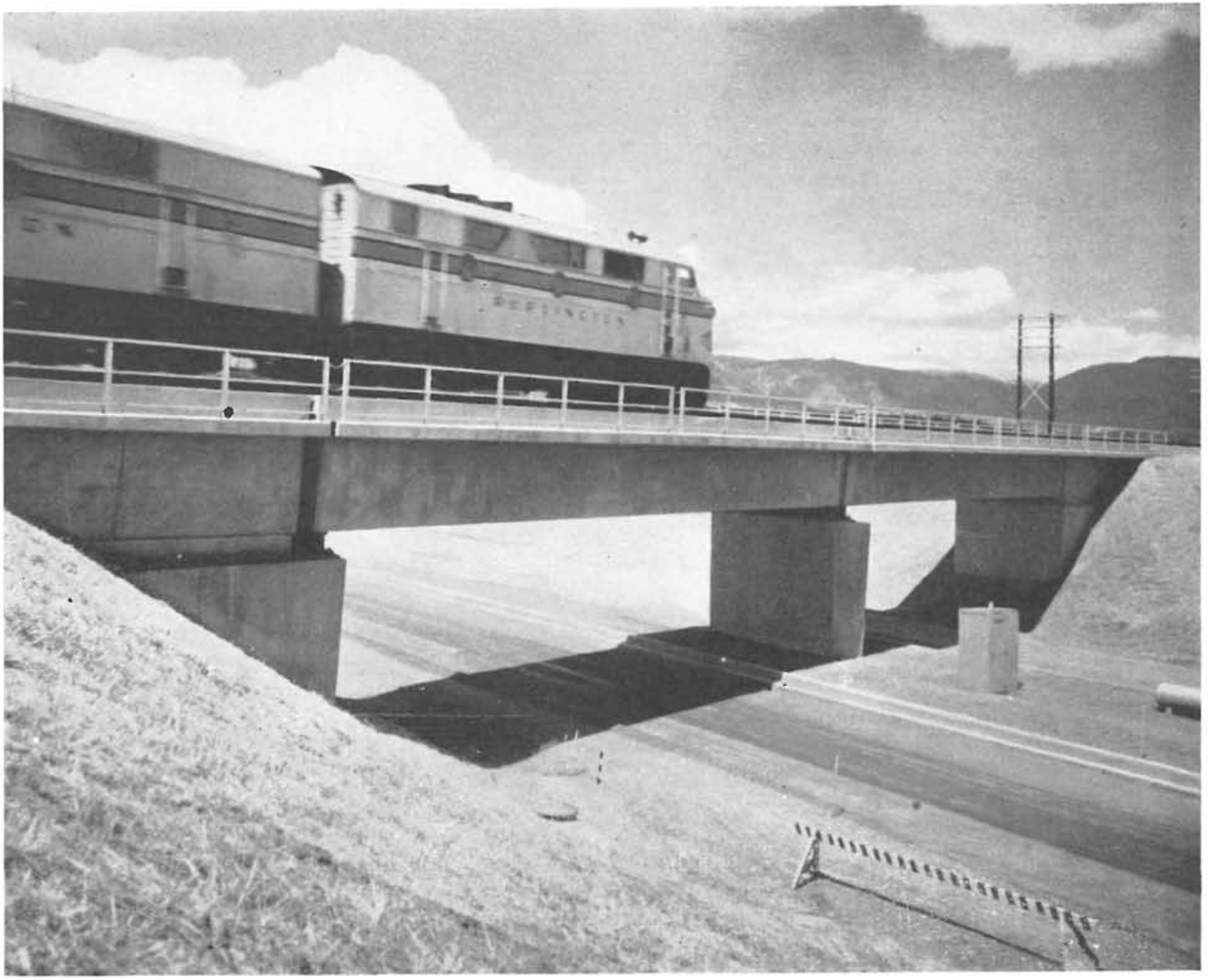

SECCION TRANSVERSAL. - LUZ 21,30

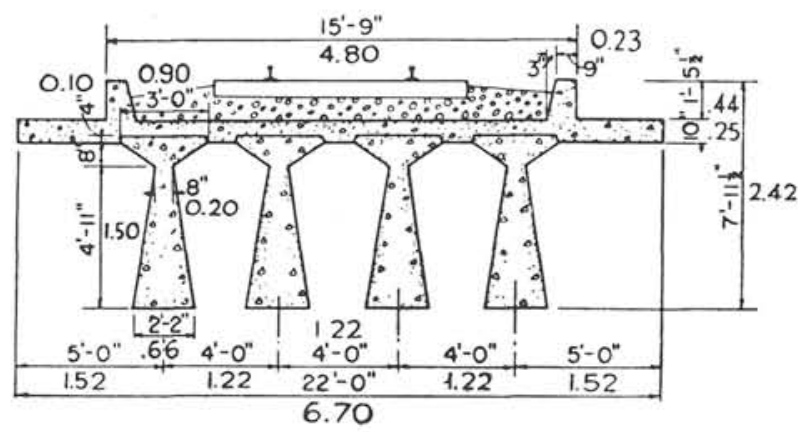

Puente Air Force Academy.-Santa e R. R.. U. S. A. 


\section{lámina $\mathrm{X}$}
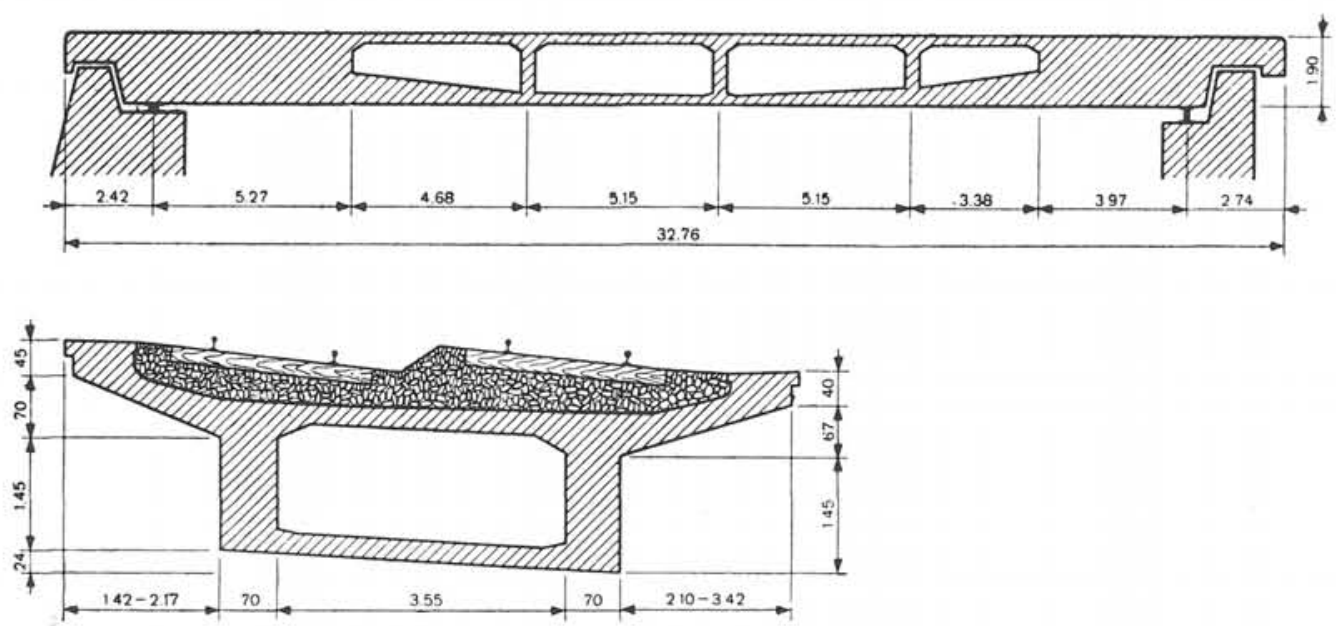

Paso superior del F. C. S. B. B. en Neuhausen, Suiza.

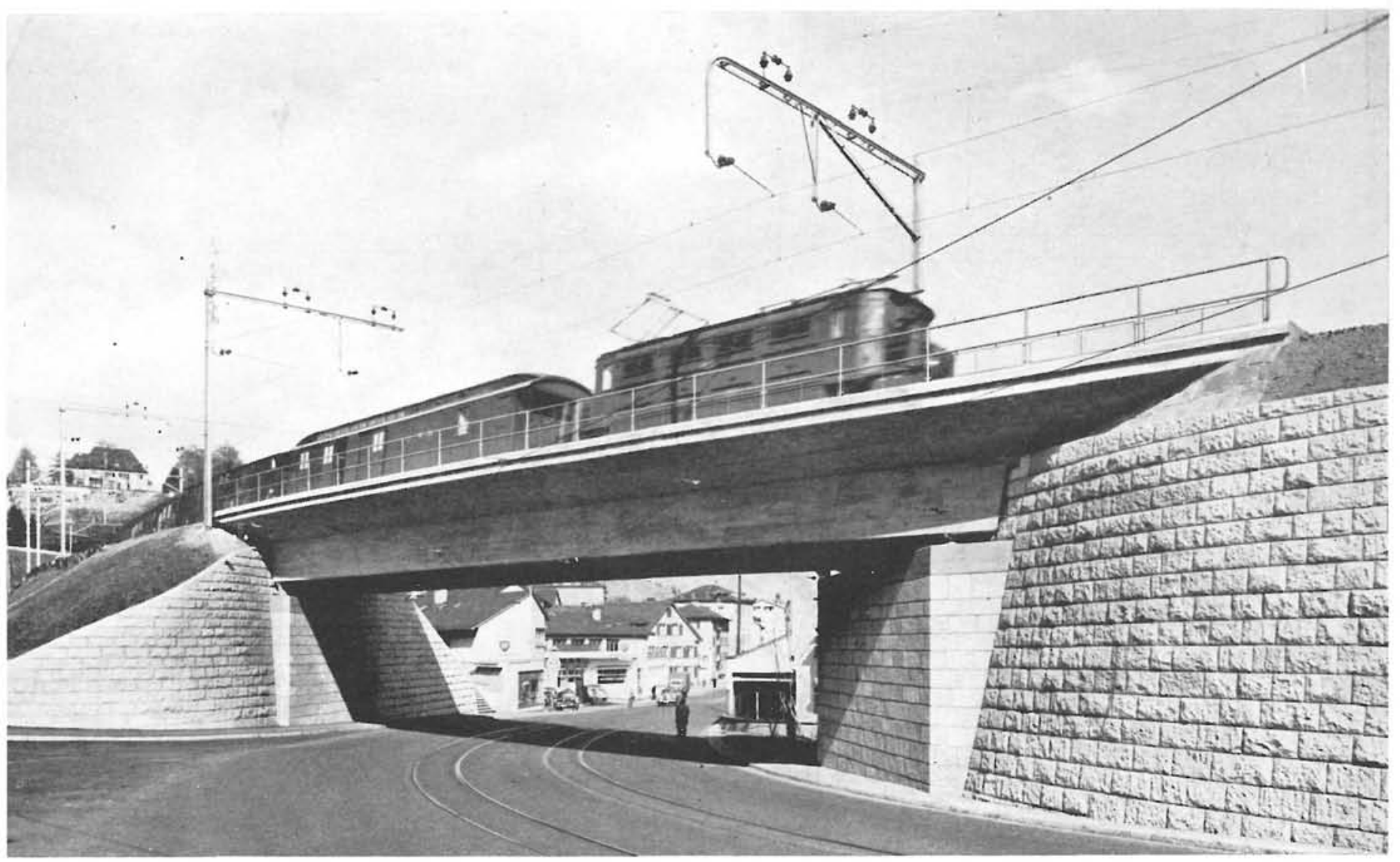


lámina XI

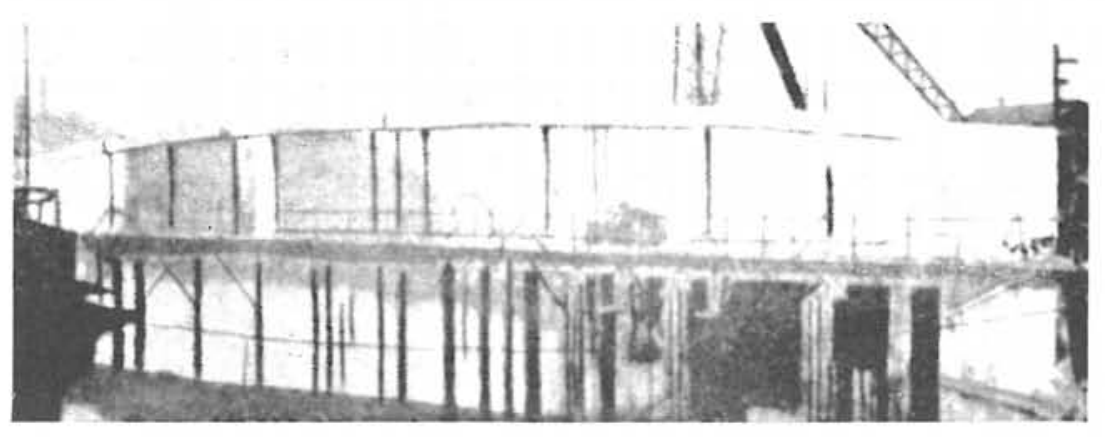

puente Roterham (Inglaterra)

SECCION TRANSVERSAL

DETALLE EXTREMIDAD
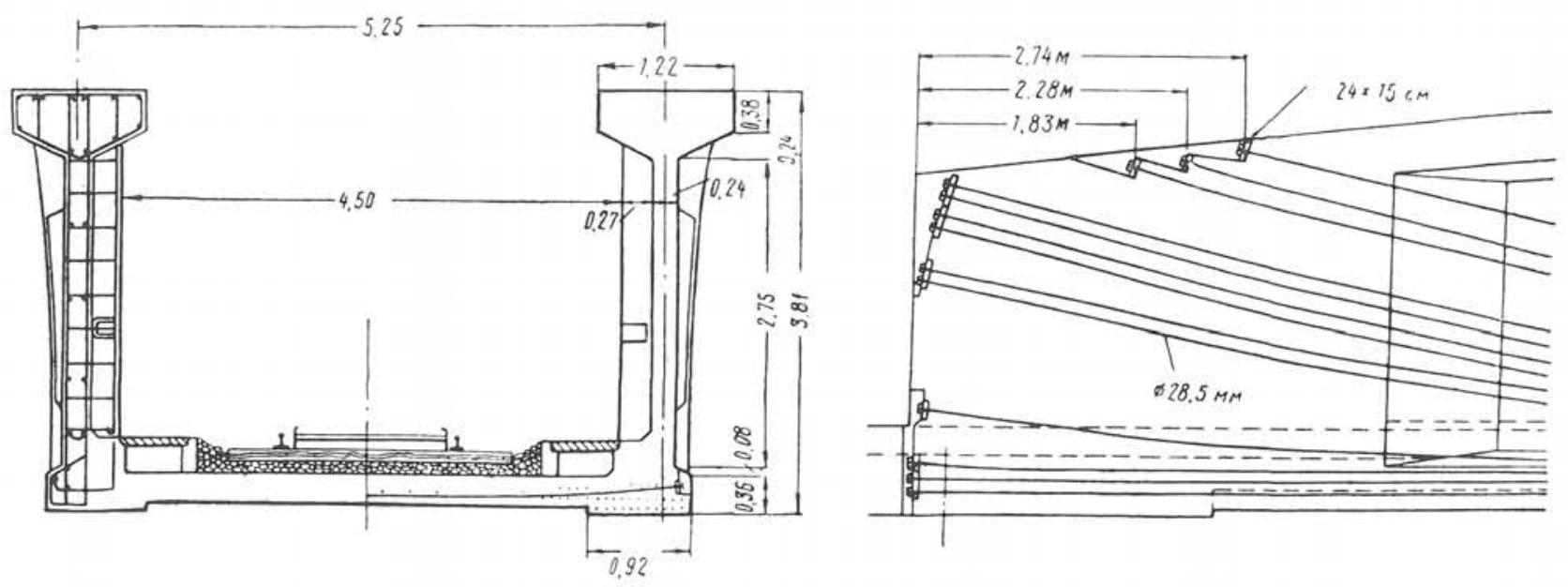

SEMIALZADO

LUZ: $48,80 \mathrm{M}$.
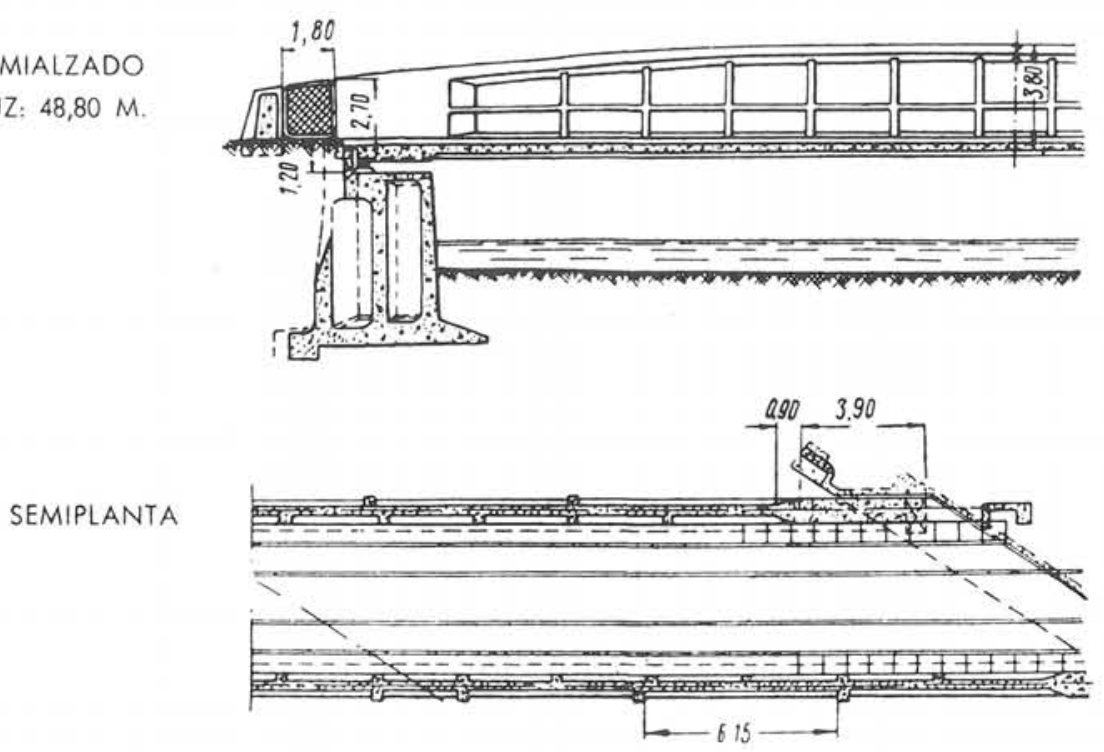

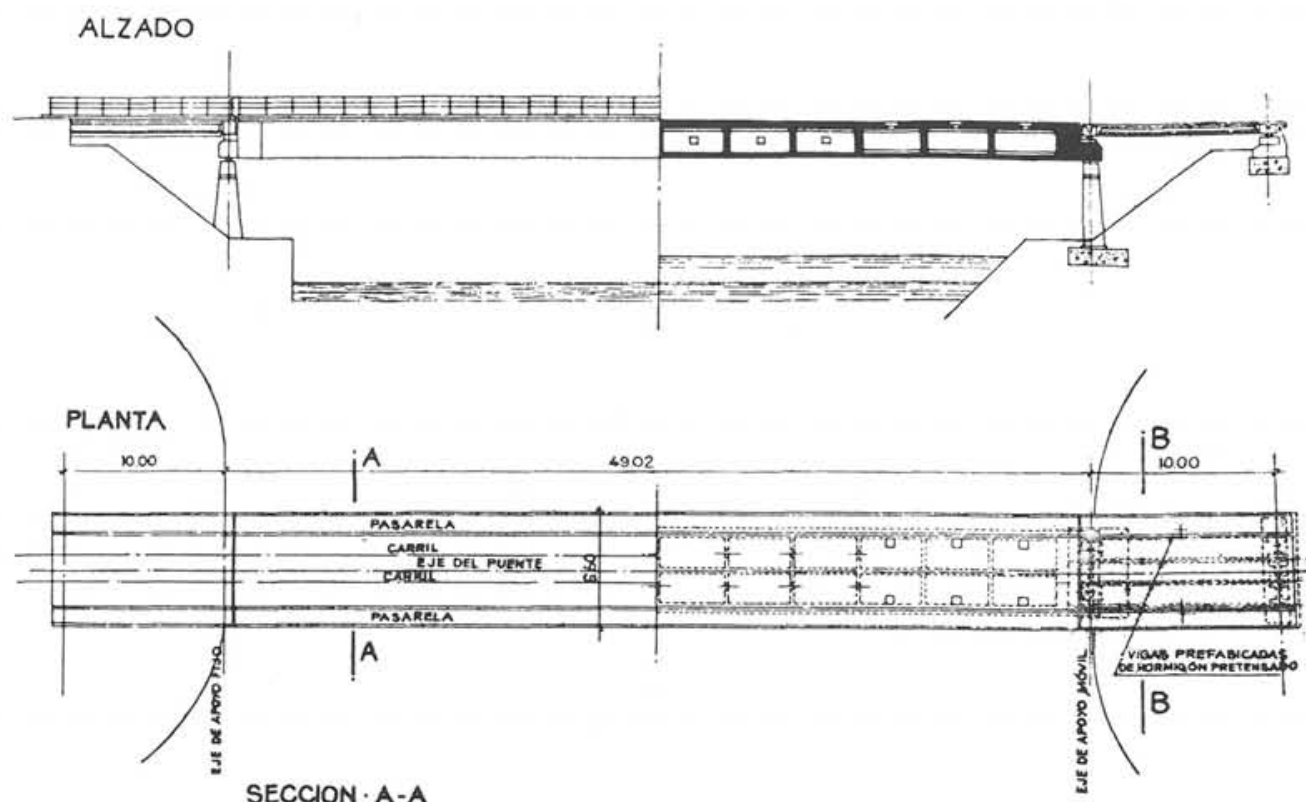

SECCION - A-A

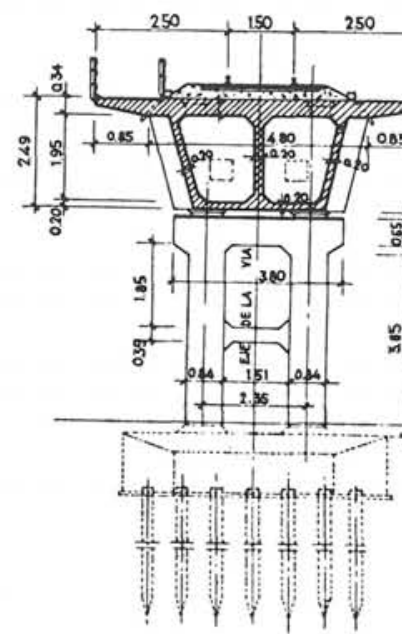

SECCION - B-B

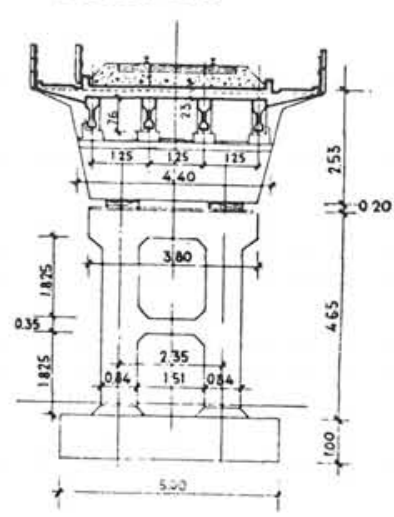

DETALLE ARMADURAS.

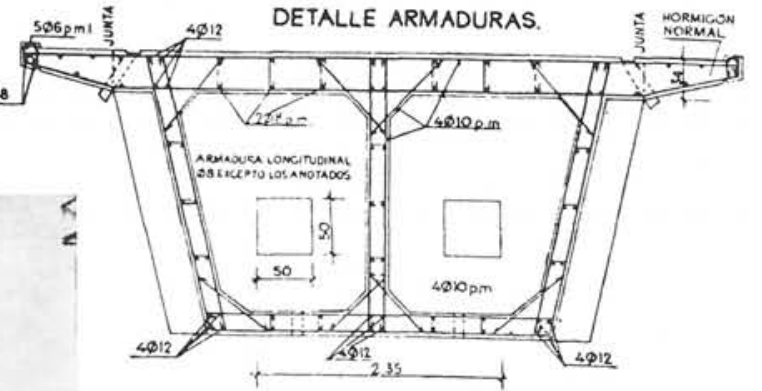




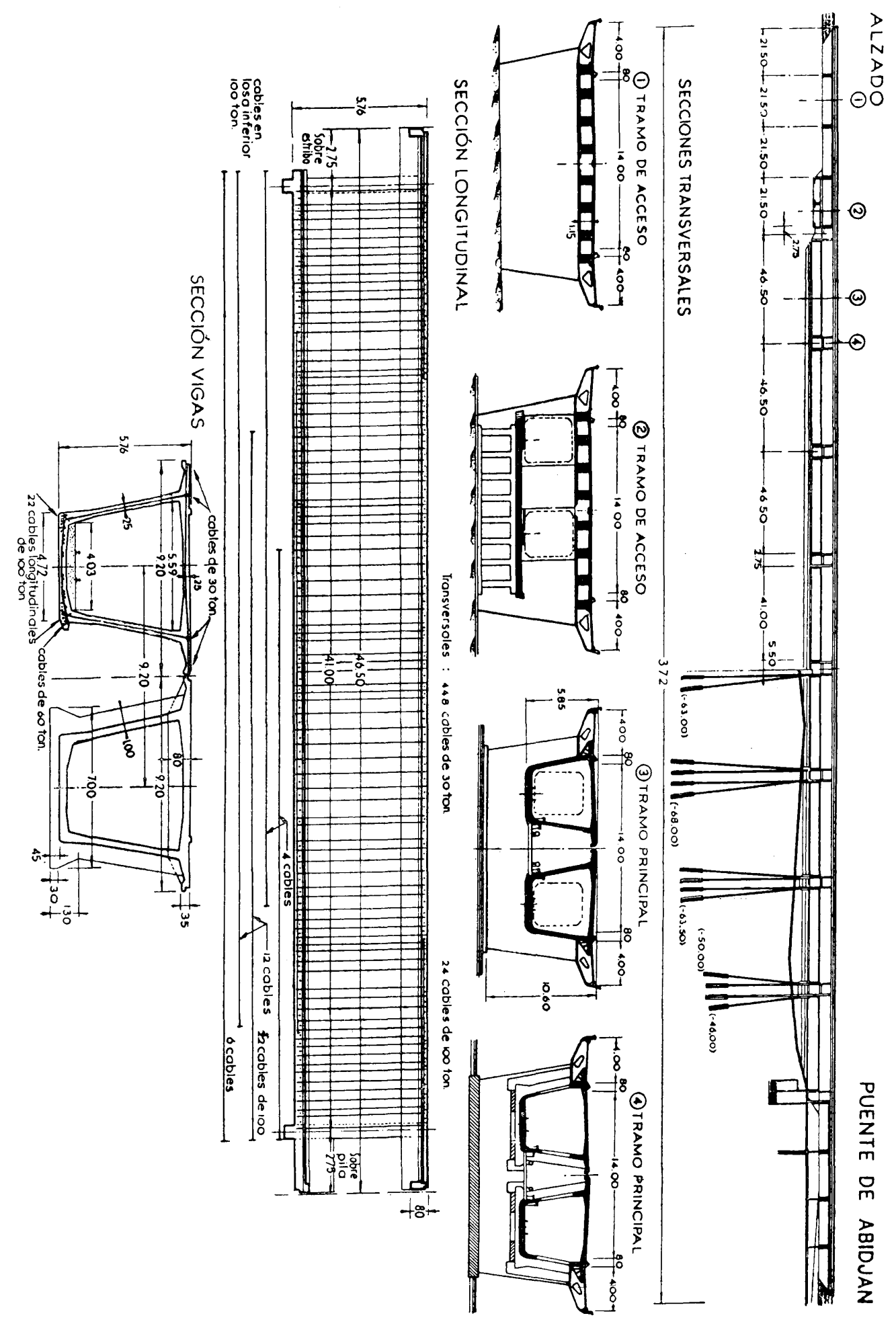

IIIX Du!tup| 


\section{Iámina XIV}

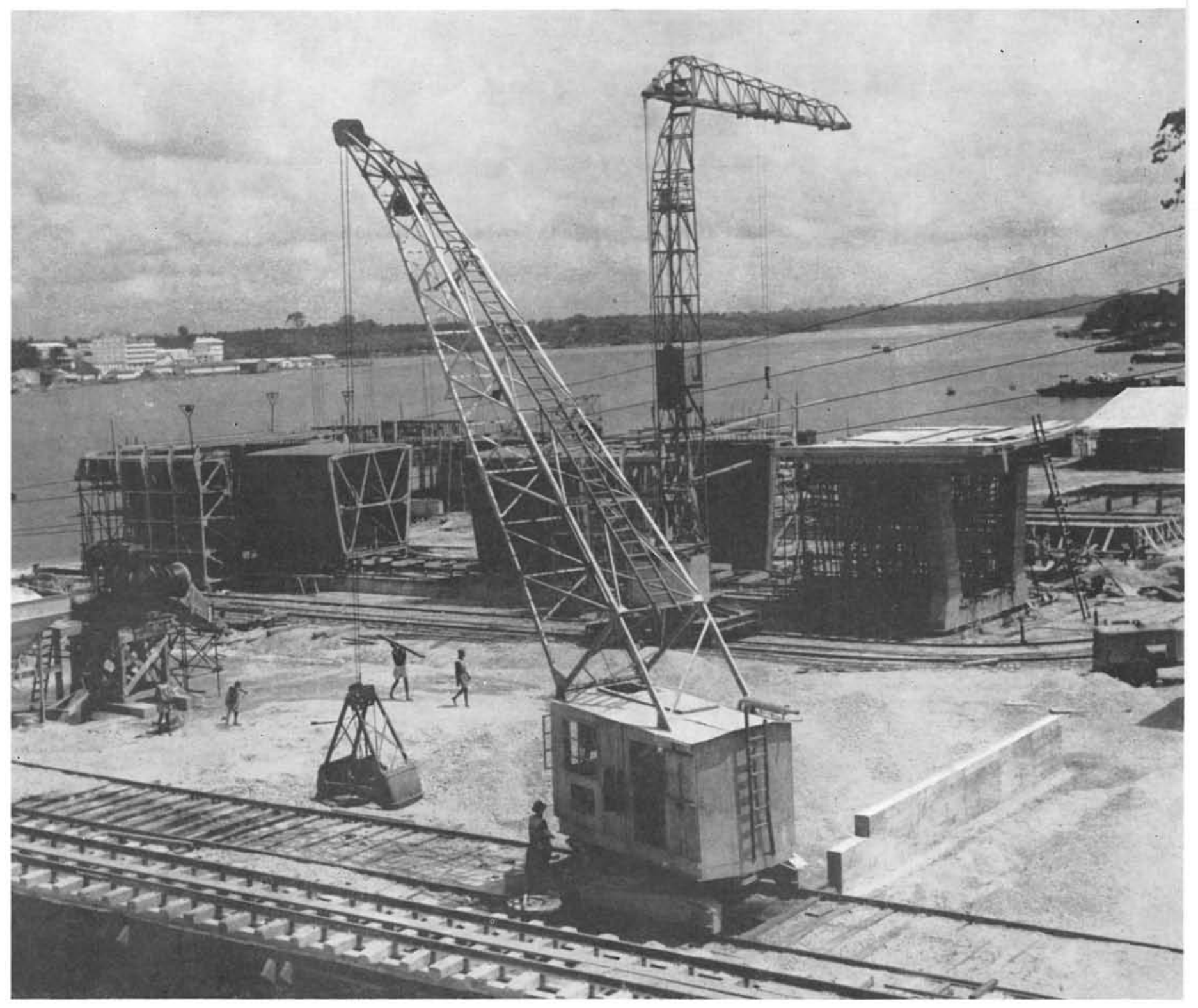

Puente de Abidjan. 

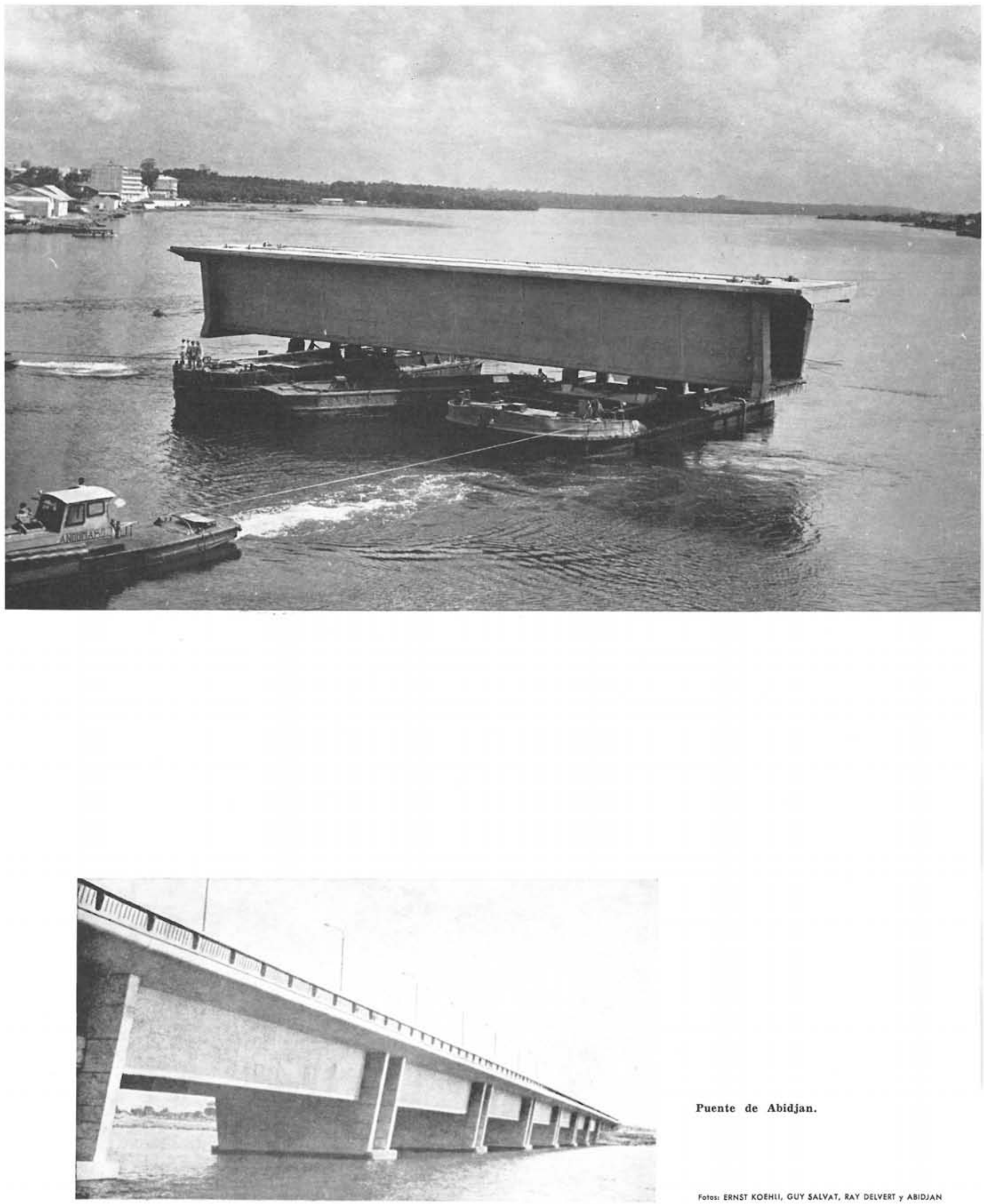

Puente de Abidjan.

\section{lámina XV}

